\title{
Restless leg syndrome among Sudanese patients with type 2 diabetes mellitus: A case-control study
}

Hyder Osman Mirghani ( $\sim$ h.mirghani@ut.edu.sa )

\section{Research note}

Keywords: Restless leg syndrome, type 2 diabetes, Glycated hemoglobin, complications, Sudan

Posted Date: January 10th, 2020

DOI: https://doi.org/10.21203/rs.2.20528/v1

License: (c) (i) This work is licensed under a Creative Commons Attribution 4.0 International License. Read Full License

Version of Record: A version of this preprint was published at Cureus on August 9th, 2020. See the published version at https://doi.org/10.7759/cureus.9635. 


\section{Abstract}

Objectives: There is an increasing awareness about the association of the restless leg syndrome (RLS) with type 2 diabetes, the present study assessed RLS and its associations among patients with diabetes.

Results: This case-control study conducted among 160 subjects (eighty-two patients with diabetes and 78 controls) attending a diabetic clinic in Omdurman, Sudan during the period from June 2018 to September 2019. A structured questionnaire based on restless syndrome, demographic data, and diabetes complications was used. The neck circumference was measured to assess adiposity, and a blood sample was taken for the glycated hemoglobin estimation. There were 82 patients with type 2 diabetes and 78 controls matched for age and sex, the restless syndrome was higher among patients with diabetes (31.7\% vs. $10.3 \% \%$ ) with significant statistical difference, $\mathrm{P}-<0.05$, A direct positive relationship was found between restless leg syndrome and diabetic neuropathy (Wald $=5.48, \mathrm{P}$ value $=0.019,95 \% \mathrm{Cl} 1.70-410.76$, no relationship was found between $\mathrm{RLS}$, diabetic retinopathy, $\mathrm{HbA} 1 \mathrm{C}$, sex, and neck circumference, P-values $(0.757,0.804,0.317$, and 0.361 respectively). RLS was prevalent among patients with type 2 diabetes and related to diabetic neuropathy, no relationship was found between restless syndrome, age, sex, neck circumference, $\mathrm{HbA} 1 \mathrm{c}$, and retinopathy.

\section{Introduction:}

Restless legs syndrome (RLS) is among the most common neurologic disorders, affecting up to $8 \%$ of adults in the developed countries and clinically significant Restless legs syndrome is estimated to affect $2-3 \%$ of the adult population $[1,2])$.

The restless leg syndrome is a relatively common morbid disorder in childhood and adolescence although it is commonly overlooked due to it's a typical presentation [3]

The pathophysiology is complex involving an iron deficiency in the dopamine neurons of the substantia nigra, these neurons project to the striatum which plays a crucial role in movement modulation. The iron levels are usually normal outside the brain. Several genes (BTBD9, Btbd9, and MEIS1) were identified as increasing the risk of restless syndrome in animal models [4]. Neuroimaging of the brain (magnetic resonance imaging, Positron emission tomography, and single positron emission computed tomography) also demonstrated the low iron not only in the substantia nigra but extending to involve the thalamus. The low iron concentration leads to nigrostriatal and mesolimbic dopaminergic pathways and in turn to sensorimotor and limbic nociceptive pathways [5]

Recent literature showed the involvement of other areas not subserving movement or sensation ( cingulate cortex and cerebellum). The pre and postcentral gyri and cerebellum were also affected and activated. In addition to the dopaminergic oxygen-sensing, opioid, glutamatergic, and serotonergic systems are involved. [6]. 
Clinically the restless leg syndrome is characterized by an urge to move the limbs accompanied by the unpleasant sensation that increase at night and relieved by movement. RLS could be primary or secondary to various disorders including iron deficiency anemia, and polyneuropathy. RLS and painful diabetic neuropathy, although similar, but they are different entities that pose a great diagnostic challenge $[7,8]$. The diagnosis is primarily clinical, and there are no diagnostic tests, the executive committee of the International Restless Legs Syndrome Study and Workshop group developed and approved four criteria that must be all present in >five times/month [9].

Diabetes mellitus is a global health burden. Currently, 285 million are affected by the disease and the projection for the year 2030 is 438 million, with Asian countries suffering the bulk of the total diabetes epidemic [10].

Most patients develop diabetes mellitus after the age of 40 years, but despite the improvement in diabetes management, comorbidities are high from its microvascular complications mainly neuropathy and nephropathy, and most die from cardiovascular disease [11, 12].

The American Diabetes recommendation is to target glycosylated hemoglobin ( $\mathrm{HbA} 1 \mathrm{c} \%$ ) to less than 7 to reduce microvascular complications in type 1 and type 2 diabetes. If metformin is used in overweight diabetic patients, the risk of myocardial infarction is also reduced $[13,14]$.

Previous studies observed that patients with diabetes have 4-4.4-times more risk of developing the restless leg syndrome than in the general population although others observed no relationship between the syndrome and diabetes mellitus. A significant association between this morbid disorder and diabetes is not unusual because of the etiologic role of diabetes in producing renal failure and polyneuropathy [9, $15,16]$. Diabetes mellitus and the restless syndrome when observed together could precipitate the other deleterious effects. Provided the controversy about the association of the restless leg syndrome and diabetes and the paucity of literature regarding this relatively common syndrome, also studies conducted in other countries may not apply to Sudan. Thus, we conducted this search. In the current study, we assess the restless syndrome among patients with type 2 diabetes mellitus.

\section{Subjects And Methods:}

\section{Research design:}

This case-control study conducted a diabetes clinic at Omdurman Teaching Hospital, Sudan during the period from June 2018 to September 2019. Eighty-two patients with type 2 diabetes diagnosed according to American Diabetes Guidelines [13]and seventy-eight healthy controls were approached. Patients with other sleep disorders or severe hypoglycemia were excluded.

Study population and sampling: One hundred-sixty participants were approached. The sample size was calculated from the formula: $n=Z^{2} P Q / d^{2}$ where $Z=95 \%$ confidence (1.96), $P=$ prevalence of diabetes mellitus in Sudan [10] 
A structured questionnaire was used to interview the study sample to collect the following information. Age, sex, diabetes microvascular complications including neuropathy, nephropathy, and retinopathy, the macrovascular complications, and if diagnosed anemia. The Restless Syndrome International Study Group Guidelines $[8,9]$ were used to diagnose the restless leg syndrome. The criteria include the presence of an unpleasant sensation in the limb with a desire to move, the unpleasant sensation increases with rest and at night and decreases with movement. The four components should be positive for the diagnosis. The diagnosis of peripheral neuropathy was based on history and abnormal clinical tests including touch and pain sensation, position and vibration sense, and ankle reflex. Nerve biopsy was not done to diagnose small fiber neuropathy. Neck circumference was measured below the laryngeal prominence and perpendicular to the long axis of the neck, and the minimal circumference is recorded to the nearest $0.1 \mathrm{~cm}$. The patients should look forward and the shoulders not elevated. Previous literature concluded that a neck circumference $>37$ in males and $34 \mathrm{~cm}$ in females are probably the best cut-offs to determine patients $[17,18]$ with central adiposity $\mathrm{A}$ blood sample was taken for $\mathrm{HbA} 1 \mathrm{c}$ measurement to assess the degree of diabetes control using the reagent from using a glycol hemoglobin reagent set from HB1C Siemens Healthcare Diagnostics Newark, DE 19714, USA.

The ethical committee of Elnour Complex, Omdurman, Sudan approved the research(Ref. 18, R 2, dated 17/5/2018). All the participants signed a written informed consent.

The Statistical Package for Social Sciences (SPSS, version 20, Chicago) was used for data analysis. The Chi-square, independent sample t-test and logistic regression analysis were used for data analysis. The data were presented as percentages and mean \pm SD, a P-value of $<0.05$ was considered significant.

\section{Results}

\section{A comparison between patients with type 2 diabetes and control subjects}

They were one hundred-sixty subjects, eighty-two patients with type 2 diabetes and seventy-eight control subjects matched for age and sex, $(63.4 \%$ vs. $51.3 \%)$ were females with no significant statistical difference, their ages were $(54.02 \pm 7.55)$ years for patients with diabetes and $(50.94 \pm 11.30)$ for control subjects with no significant statistical difference, P-value $=0.155$, the restless syndrome was higher among patients with diabetes ( $31.7 \%$ vs. $10.3 \% \%$ ) with significant statistical difference, P-value $=0.019$. Table 1 depicted a comparison between patients with diabetes and control subjects.

\section{The relationship of the restless syndrome ( $\mathrm{No}=26)$ to diabetes neuropathy, retinopathy, and sex}

Table 2. showed a comparison between patients with diabetes mellitus and restless leg syndrome and their counterparts without RLS. RLS was commoner among patients with peripheral neuropathy $(69.2 \%$ 
vs. 14.8) with a significant statistical difference, $P$-value $=001$, no significant statistical difference was evident regarding diabetic retinopathy, age, sex, and abnormal neck circumference. However a higher numerical value was observed regarding the glycated hemoglobin $(10.04 \pm 2.53$ vs. $8.51 \pm 1.62$, Pvalue $=0.077$.

The relationship of the restless syndrome $(\mathrm{No}=26)$ to sex, neck circumference, diabetes neuropathy, retinopathy, and HbA1c

A direct positive relationship was found between restless leg syndrome and diabetic neuropathy (Wald $=5.48$, P-value $=0.019,95 \% \mathrm{Cl} 1.70-410.76$, no relationship was found between RLS, diabetic retinopathy, $\mathrm{HbA} 1_{c}$, sex, and neck circumference, P-values $(0.757,0.804,0.317$, and 0.361 respectively). Table 3 .

Table 1. A comparison between patients with type 2 diabetes and control subjects

\begin{tabular}{lllll} 
Character & Diabetes & controls & P-value & $95 \% \mathrm{Cl}$ \\
\hline Age & $54.02 \pm 7.55$ & $50.94 \pm 11.30$ & 0.155 & $-1.18-7.33$ \\
\hline Restless leg score & $1.49 \pm 1.81$ & $0.45 \pm 1.10$ & 0.003 & $0.37-1.71$ \\
\hline Sex & & & 0.273 & $0.249-1.48$ \\
$\quad$ Males & $30(36.6 \%)$ & $38(48.7 \%)$ & & \\
$\quad$ Females & $52(63.4 \%)$ & $40(51.3 \%)$ & & \\
\hline Restless leg syndrome & $26(31.7 \%)$ & $8(10.3 \%)$ & 0.019 & $1.19-13.84$ \\
\hline Abnormal neck circumference & $60(81.1 \%)$ & $42(26.9 \%)$ & 0.012 & $1.30-10.35$
\end{tabular}




\begin{tabular}{lllll} 
Character & RLS $=26$ & No RLS $=54$ & P-value & $95 \% \mathrm{Cl}$ \\
\hline Age & $53.92 \pm 9.33$ & $54.00 \pm 6.89$ & 0.977 & $-5.37-5.21$ \\
\hline Sex & & & 0.298 & $0.883-2.17$ \\
$\quad$ Males & $6(23.1 .8 \%)$ & $24(44.4 \%)$ & & \\
$\quad$ Females & $20(76.9 \%)$ & $30(55.5 \%)$ & & \\
\hline Neuropathy & $18(69.2 \%)$ & $8(14.8 \%)$ & 0.001 & $0.16-0.377$ \\
\hline Retinopathy & $6(23.1 \%)$ & $6(11.5 \%)$ & 0.321 & $0.072-2.42$ \\
\hline Abnormal neck circumference & $24(92.3 \%)$ & $36(75 \%)$ & 0.199 & $0.42-37.55$ \\
\hline HbA1 & $10.04 \pm 2.53$ & $8.51 \pm 1.62$ & 0.077 & $-.175-3.22$
\end{tabular}

Table 3.The relationship of the restless syndrome $(\mathrm{No}=26)$ to sex, neck circumference, diabetes neuropathy, retinopathy, and HbA1c

\begin{tabular}{lllll} 
Character & Wald & df & P-value & $95 \% \mathrm{Cl}$ \\
\hline Neuropathy & 5.48 & 1 & 0.019 & $1.70-410.76$ \\
\hline Retinopathy & 0.096 & 1 & 0.757 & $0.118-18.84$ \\
\hline HbA1c & 0.061 & 1 & 0.804 & $0.533-1.62$ \\
\hline Sex & 1.000 & 1 & 0.317 & $0.46-10.95$ \\
\hline Neck circumference & 0.834 & 1 & 0361. & $0.033-3.61$ \\
\hline Constant & 0.005 & 1 & 0.946 &
\end{tabular}

- ${ }^{*}$ Logistic regression analysis

\section{Discussion}

Several studies have documented the high prevalence of restless leg syndrome among patients with type 2 diabetes; the association cannot be explained by the presence of peripheral neuropathy alone, another 
theory is the prolonged sleep loss that could lead to insulin resistance and metabolic disturbances [19]. In the present study, restless leg syndrome was found in $31.7 \%$ of patients compared to $10.3 \%$ of control subjects, the present finding was higher than the result of (Harashima et al.[20] (8\%), The current findings were similar to a study published by Zobeiri et al.[21] who concluded a prevalence of $28.6 \%$ compared to $7.1 \%$ in control subjects. Previous studies from other countries found lower rates of RLS among patients with diabetes [22, 23]. A previous study [24] showed no association of the restless leg syndrome with type 2 diabetes in contradiction to the current findings. The different rates of RLS may be explained by other comorbidities and study type [25]. In the current study, peripheral neuropathy was associated with the restless syndrome in line with a previous observation [20]. The symptoms of the restless syndrome and peripheral neuropathy are similar and aggravate each other deleterious effects, this similarity may lead to misdiagnosis and delayed treatment. Furthermore, small fiber neuropathy may be a risk factor for the restless syndrome [26-28]. The current study findings imply the importance of the earlier detection of the restless syndrome because it is a treatable condition that aggravates diabetic neuropathy and negatively affects quality of life and sleep. Previous researchers concluded that restless syndrome through sleep disturbances and psychological factors could impair glycemic control [29], the current finding of a numerically higher (not reaching statistical difference) glycated hemoglobin among patients with restless leg syndrome contradict these observations. In the present study, no relationship was found between the restless syndrome, sex, retinopathy, and neck circumference in similarity to a survey carried out in Colombia [30] and concluded similar results. The present findings are in contradiction to Medeiros et al. [31]who concluded a high neck circumference among restless leg syndrome patients. Racial, behavioral, and environmental factors may explain the differences [30, 31]

Conclusion: restless leg syndrome is prevalent in patients with type 2 diabetes and associated with peripheral neuropathy.

Study limitations: The study limitations are the fact that the survey was conducted at a single diabetes clinic so generalization cannot be insured. Further larger studies to investigate the risks associated with this common sleeping disorder are highly recommended. Raising the physician's awareness about this underdiagnosed syndrome could improve the

\section{Declarations}

\section{Authors contribution}

$\mathrm{HM}$, designed the study, recruited the patients, drafted the manuscript, and revised it critically before submission

\section{Acknowledgment}

The author would like to acknowledge Dr. Yasin Ibrahim, Assistant Prof. of Community Medicine, Medical College, University of Tabuk, Saudi Arabia for data analysis 


\section{Competing interests}

The author declares that they have no competing interests.

\section{Availability of data}

All the data of the current project were presented within the manuscript.

\section{Consent to publish}

Not applicable

\section{Ethical consideration}

Ethical approval was obtained from the ethical committee of Elnour complex (Ref. 18, R 2, dated 17/5/2018). A written informed consent was obtained from all the participants.

Funding: The study was not supported by any institute or organization

\section{References}

1.

Harashima S, Nishimura A, Osugi T, Wang Y. Liu Y`, Takayama Het al. Restless legs syndrome in patients with type 2 diabetes: effectiveness of pramipexole therapy.BMJ Support Palliat Care. 2016 Mar;6(1):8993. doi: 10.1136/bmjspcare-2014-000691. Epub 2014 Sep 12.

2.

Allen RP, Bharmal M, Calloway M. Prevalence and disease burden of primary restless legs syndrome: results of a general population survey in the United States. Mov Disord. 2011;26:114-20. doi:10.1002/mds.23430.

3.

Angriman M, Cortese S, Bruni O. Somatic and neuropsychiatric comorbidities in pediatric restless legs syndrome: A systematic review of the literature. Sleep Med Rev. 2016. doi:10.1016/j.smrv.2016.06.008. [Epub ahead of print]. Jul 1. pii: S1087-0792(16)30060-0.

4.

Allen RP, Donelson NC, Jones BC, Li Y, Manconi M, Rye DB, Sanyal S, Winkelmann J. Animal models of RLS phenotypes. Sleep Med. 2016 Sep 2. pii: S1389-9457(16)30116-2. doi: 10.1016/j.sleep.2016.08.002. [Epub ahead of print].

5.

Rizzo G, Li X, Galantucci S, Filippi M, Cho YW. Brain imaging and networks in restless legs syndrome. Sleep Med. 2016. doi:10.1016/j.sleep.2016.07.018. [Epub ahead of print]. Aug 29. pii: S13899457(16)30135-6.

6. 
Koo BB ${ }^{1}$, Bagai K, Walters AS. Restless Legs Syndrome: Current Concepts about Disease Pathophysiology. Tremor Other HyperkinetMov (N Y). 2016 Jul 22;6:401. doi: 10.7916/D83J3D2G. eCollection 2016.

7.

Trotti LM, Becker LA. Iron for the treatment of restless legs syndrome.Cochrane Database Syst Rev. 2019 Jan 4;1:CD007834. doi: 10.1002/14651858.CD007834.pub3.

8.

Kalra S, Gupta A. Diabetic Painful Neuropathy and Restless Legs Syndrome in Diabetes. Diabetes Ther. 2018 Apr;9(2):441-7. doi:10.1007/s13300-018-0376-6. Epub 2018 Feb 9.

9.

Allen RP, Picchietti D, Hening WA, et al. Restless legs syndrome: diagnostic criteria, special considerations, and epidemiology. A report from the restless legs syndrome diagnosis and epidemiology workshop at the National Institutes of Health. Sleep Med. 2003;4(2):101-19.

10 .

International Diabetes Federation. Middle East, and North Africa 2015.

11.

Simpson S, Corabian P, Jacobs P, Johnston JA. The cost of major co morbidity in people with diabetes mellitus. Can Med Assoc J. 2003;168:1661-7.

12.

Assmann G, Nofer JR, Schulte H. Cardiovascular risk assessment in metabolic syndrome: view from PROCAM. Endocrinol Metab Clin North Am. 2004;33:377-92.

13.

American Diabetes Association. Classification and Diagnosis of Diabetes: Standards of Medical Care in Diabetes-2019. Diabetes Care. 2019 Jan;42(Supplement 1):13-28. .https://doi.org/10.2337/dc19-S002. 14.

Effects of intensive blood-glucose control with metformin on complications in overweight patients with type 2 diabetes (UKPDS) Group. Lancet 1998;352; $854-65$.

15.

Merlino G, Fratticci L, Valente M, et al., "Association of restless leqs syndrome in type 2 diabetes: a casecontrol study" Sleep, vol. 30, no. 7, pp. 866-871, 2007.

16.

Lai SC, Chen RS. Restless legs syndrome. Acta Neurologica Taiwanica. 2008;17(1):54-65.

17.

Yang GR, Yuan SY, Fu HJ, Wan G, Zhu LX, Bu XL. Neck circumference positively related with central obesity, overweight, and metabolic syndrome in chinese subjects with type 2 diabetes: Beijing community diabetes study 4. Diabetes Care. 2010;33:2465-7.

18.

Aswathappa J, Garg S, Kutty K, Shankar V. Neck circumference as an anthropometric measure of obesity in diabetics. N Am J Med Sci. 2013 Jan;5(1):28-31. doi:10.4103/1947-2714.106188.

19. 
Greco D. [Restless legs syndrome and diabetes mellitus: an accidental association?].RecentiProg Med. 2011 May;102(5):212-6. doi: 10.1701/659.7671.

[Article in Italian].

20.

Harashima S, Nishimura A, Osugi T, Wang Y, Liu Y, Takayama H, Inagaki N. Restless legs syndrome in patients with type 2 diabetes: effectiveness of pramipexole therapy. BMJ Support Palliat Care. 2016 Mar;6(1):89-93. doi:10.1136/bmjspcare-2014-000691. Epub 2014 Sep 12.

21.

Zobeiri M, Shokoohi A. Restless leg syndrome in diabetics compared with normal controls. Sleep Disord. 2014;2014:871751. doi:10.1155/2014/871751. Epub 2014 May 7.

22.

Modarresnia L, Golgiri F, Madani NH, Emami Z, Tanha K. Restless Legs Syndrome in Iranian People With Type 2 Diabetes Mellitus: The Role in Quality of Life and Quality of Sleep. J Clin Sleep Med. 2018 Feb;15(2):223-8. doi:10.5664/jcsm.6938. 14 ) .

23.

Šiarnik P, Klobučníková K, Šurda P, Putala M, Šutovský S, Kollár B, et al. Excessive Daytime Sleepiness in Acute Ischemic Stroke: Association With Restless Legs Syndrome, Diabetes Mellitus, Obesity, and SleepDisordered Breathing. J Clin Sleep Med. 2018 Jan 15;14(1):95-100. doi: 10.5664/jcsm.6890.

24.

Sabic A, Sinanovic O, Sabic D, Galic G. Restless Legs Syndrome in Patients with Hypertension and Diabetes Mellitus. Med Arch. 2016 Apr;70(2):116-8. doi:10.5455/medarh.2016.70.116-118. Epub 2016 Apr 1.

25.

Merlino G, Fratticci L, Valente M, et al. Association of restless legs syndrome in type 2 diabetes: a casecontrol study. Sleep. 2007;30:866-71.

26.

Pitarokoili K, Fels M, Kerasnoudis A, Tönges L, Gold R, Yoon MS. High-Resolution Nerve Ultrasound and Electrophysiological Findings in Restless Legs Syndrome. J Neuroimaging. 2018 Sep;28(5):506-14. doi:10.1111/jon.12520. Epub 2018 May 11.

27.

Cuellar NG, Dorn JM. Peripheral diabetic neuropathy or restless legs syndrome in persons with type 2 diabetes mellitus: Differentiating diagnosis in practice. J Am Assoc Nurse Pract. 2015 Dec;27(12):671-5. doi:10.1002/2327-6924.12311. Epub 2015 Oct 14.

28.

Gemignani F, Vitetta F, Brindani F, Contini M, Negrotti A. Painful polyneuropathy associated with restless legs syndrome. Clinical features and sensory profile. Sleep Med. 2013 Jan;14(1):79-84. doi: 10.1016/j.sleep.2012.08.013. Epub 2012 Oct 4.

29.

Merlino G, Valente M, Serafini A, Fratticci L, Del Giudice A, PianiA, Noacco C, Gigli GL. Effects of restless legs syndrome on quality of life and psychological status in patients with type 2 diabetes. Diabetes Educ. 
2010 Jan-Feb;36(1):79-87. doi: 10.1177/0145721709351252.

30.

Ruiz AJ, RondonSepúlveda MA, Franco OH, Cepeda M, Hidalgo Martinez P, Amado Garzón SB, Salazar Ibarra ER, Otero Mendoza L. The associations between sleep disorders and anthropometric measures in adults from three Colombian cities at different altitudes. Maturitas. 2016 Dec;94:1-10. doi:

10.1016/j.maturitas.2016.08.013. Epub 2016 Aug 20.

31.

Medeiros CA, de Bruin PF, Paiva TR, Coutinho WM, Ponte RP, de Bruin VM. Clinical outcome after acute ischaemic stroke: the influence of restless legs syndrome. Eur J Neurol. 2011 Jan;18(1):144-9. doi:10.1111/j.1468-1331.2010.03099.x.

\section{Abbreviations}

RLS: Restless leg syndrome

$\mathrm{HbA} 1_{\mathrm{c}}:$ The glycated hemoglobin 